\title{
Influência de variáveis limnológicas sobre a comunidade das macrófitas aquáticas em rios e lagoas da Cadeia do Espinhaço, Minas Gerais, Brasil ${ }^{1}$
}

\author{
The effect of limnological variables on the macrophyte community in rivers and lakes \\ of the Espinhaço Range, Minas Gerais state, Brazil
}

\author{
Sylvia Therese Meyer ${ }^{2,4} \&$ Edivani Villaron Franceschinelli ${ }^{3}$
}

\begin{abstract}
Resumo
Plantas aquáticas e amostras de água foram coletadas em cinco lagoas e três rios na região da Cadeia do Espinhaço, entre dezembro de 2001 e agosto de 2003. Lagoas: Tanque da Fazenda, Comprida, Arame, Americana e Estivinha. Rios: Corrento, Taquaral e Preto. Foram medidas as seguintes variáveis: temperatura da água, transparência da coluna de água, $\mathrm{pH}$, condutividade elétrica, oxigênio dissolvido, demanda bioquímica de oxigênio, demanda química de oxigênio, nitrogênio amoniacal, nitrogênio total, fósforo reativo solúvel e fosfato total. Nos ambientes lóticos os maiores valores de condutividade foram registrados para os rios Preto e Corrento e foram correlacionados ao aporte de nutrientes naturais. Considerando os ambientes lênticos, nas lagoas Americana e Estivinha foram verificados os maiores valores de condutividade elétrica e DQO. O maior valor de transparência foi observado na lagoa Tanque da Fazenda. Na ordenação das espécies, foi observada maior riqueza de macrófitas junto às lagoas Americana, Estivinha e Comprida, cujas correlações mais fortes foram com os valores de temperatura, $\mathrm{pH}$ e concentração de nitrogênio. A ordenação das formas biológicas sugeriu a presença de espécies flutuantes fixas nos ambientes mais ricos em nitrogênio e com temperaturas da água mais elevadas. Provavelmente, a diversidade de ambientes identificada neste estudo e as diferentes características físicas e químicas estão refletidas na composição florística e nas interações com o ecossistema. Palavras-chave: áreas úmidas, qualidade da água, relações espécies ambiente.
\end{abstract}

\begin{abstract}
Aquatic plants and water were collected in five ponds and three rivers in the Espinhaço Range, during the period between December 2001 to August 2003. Ponds: Tanque da Fazenda, Comprida, Arame, Estivinha and Americana. Rivers: Corrento, Taquaral and Preto. The following variables were measured: water temperature, transparency, $\mathrm{pH}$, electrical conductivity, dissolved oxygen, oxygen biochemical demand, oxygen chemical demand, ammoniacal nitrogen, total nitrogen, soluble reactive phosphorous, and total phosphate. In the lothic environmental conductivity values were recorded for Corrento e Preto riverrs and were correlated to the supply of natural nutrients. Considering lenthic environments, Americana e Estivinha ponds showed higher values of electrical conductivity and OCD. The highest value of water transparency was found in the Tanque da Fazenda pond. In the ordering of species, higher richness of macrophytes was observed in the ponds Americana, Estivinha, and Comprida. These presented stronger correlation with the values of temperature, $\mathrm{pH}$ and nitrogen concentration. The ordination of biological form suggested that floating species are more common in environments rich in nitrogen and of warmer water. Probably, the diversity of environments found in this study, with different physical and chemical characteristics are reflected in the floristic composition and ecosystem function.
\end{abstract}

Key words: aquatic macrophyte, water quality, relationships environment and species, wetlands.

\footnotetext{
${ }^{1}$ Parte da tese de Doutorado da primeira autora, Programa de Pós-Graduação em Biologia Vegetal do Departamento de Botânica da Universidade Federal de Minas Gerais, MG, Brasil.

${ }^{2}$ Fundação Centro Tecnológico de Minas Gerais, Cetec, Av. José Cândido da Silveira 2000, 31035-536, Belo Horizonte, MG, Brasil.

${ }^{3}$ Universidade Federal de Goiás, Depto. Biologia Geral, ICB, Campus Samambaia, 74690-900, Goiânia, GO, Brasil.

${ }^{4}$ Autor para correspondência: sylvia.meyer@cetec.br
} 


\section{Introdução}

Ambientes aquáticos são influenciados pela geologia, clima e interferência humana, sendo considerados ecossistemas complexos, abrigando diferentes comunidades (Sculthorpe 1967). Tal como em outros ambientes naturais onde a diversidade está frequentemente relacionada com a heterogeneidade abiótica (Pollock et al. 1998), ambientes aquáticos constituem mosaicos de microhabitats (Neiff 1997), cuja estabilidade e diversidade estão condicionadas principalmente pelas condições físico-químicas da água (Murphy 2000). Entre os fatores abióticos que podem condicionar o crescimento, ocorrência e riqueza das macrófitas aquáticas estão principalmente: a temperatura, os nutrientes e a luminosidade (Bianchini Jr. 2003), além da velocidade da corrente (Camargo et al. 2003) e do nível da água (Rørslett 1988), e também da estrutura e do tipo de substrato onde elas se fixam (Pollock et al. 1998). Por sua vez, as macrófitas aquáticas podem condicionar as propriedades físico-químicas da água, disponibilizando nutrientes do sedimento para a coluna de água via excreção e decomposição de biomassa (Meerhoff \& Mazzeo 2004) ou via absorção de nitrogênio por associação com micro-organismos fixadores (Esteves 1998a); removendo-o da coluna de água, como fazem as flutuantes livres em ambientes eutrofizados (Henry-Silva \& Camargo 2000). Estas plantas também podem agir como barreiras físicas ao material alóctone (Esteves 1998b).

No estudo realizado por Drummond et al. (2005), regiões da Cadeia do Espinhaço foram indicadas como áreas prioritárias para a conservação da biodiversidade no estado de Minas Gerais. Tais ambientes montanhosos apresentam gradientes climáticos que propiciam a ocorrência de ecossistemas distintos ao longo das encostas, entre os quais figuram ambientes aquáticos com elevada riqueza de espécies, algumas endêmicas.

Embora a partir da década de 90, tenha havido incremento de estudos sobre plantas aquáticas no Brasil, motivado principalmente por suas funções ecológicas e pela demanda de controle de determinadas espécies, ainda são escassos os trabalhos que abordam sua ecologia (Thomaz \& Bini 1999). Tais estudos são importantes para a discussão de aspectos relativos à abrangência e conservação de suas espécies. Neste sentido, o presente estudo busca analisar e correlacionar as variáveis físico-químicas das águas e físicas dos ambientes com a diversidade de plantas aquáticas ocorrentes em áreas úmidas na Cadeia do Espinhaço.

\section{Material e Métodos}

A Cadeia do Espinhaço, no estado de Minas Gerais, compreende um grupo de serras localizado no centro norte deste estado. Possui limite sul no Quadrilátero Ferrífero e o limite norte prolonga-se pelo interior da Bahia (CETEC 1983). Sua extensão total corresponde a $1.100 \mathrm{~km}$, com largura entre $50 \mathrm{a}$ $100 \mathrm{~km}$ (Giulietti et al. 1987). Segundo Drummond et al. (2005), devido a grande variação latitudinal da Serra do Espinhaço e seus prolongamentos, associam-se a ela diversos tipos climáticos e vegetacionais. Desta forma, está situada a leste na transição entre o Cerrado e a Mata Atlântica, a oeste (Serra do Cabral) no bioma Cerrado e a norte no contato entre os biomas Caatinga e Cerrado. Constitui, ainda, o grande divisor de águas entre as bacias do rio São Francisco, a oeste, e do rio Doce e rio Jequitinhonha a leste.

Foram estudadas oito áreas na região da Cadeia do Espinhaço, compreendendo ambientes lóticos e lênticos. O limite sul da área de estudo está localizado no município de Mariana e o limite norte no município de Riacho dos Machados (Fig.1, Tab.1). As áreas estudadas foram as seguintes: a) ambientes lênticos - lagoa Americana (AMER), lagoa Arame (ARAM), lagoa Comprida (COMP), lagoa Estivinha (ESTI), lagoa Tanque da Fazenda (TANQ); b) ambientes lóticos - rio Corrento (CORR), rio Preto (PRET) e rio Taquaral (TAQU).

As amostras de água foram coletadas no período de dezembro de 2001 a agosto de 2003, totalizando sete campanhas de campo. Foram medidas as variáveis: (1) físicas: temperatura da água e transparência da coluna de água; (2) físicoquímicas: $\mathrm{pH}$ e condutividade elétrica da água; e (3) químicas: oxigênio dissolvido (OD), demanda bioquímica de oxigênio (DBO), demanda química de oxigênio (DQO), nitrogênio amoniacal, nitrogênio total, fósforo reativo solúvel (PRS) e fósforo total presentes na água. Foram calculadas as médias e os desvios-padrão das variáveis para cada área de amostragem, considerando o total de campanhas $(\mathrm{n}=7)$. Os métodos de amostragem e de análise das variáveis foram fundamentados no "Standard Methods for the Examination of Waste and Wast Water" (APHA 1995), com adaptações. A transparência da coluna d'água foi medida utilizandose o disco de Secchi, para os ambientes lênticos.

A matriz de variáveis físico-químicas da água foi composta pelo cálculo das médias de todas as coletas para: temperatura da água, oxigênio dissolvido, $\mathrm{pH}$, condutividade elétrica, DBO, DQO, 
Tabela 1 - Áreas de amostragem na Cadeia do Espinhaço (Minas Gerais, Brasil) e suas respectivas informações geográficas. LE = lêntico; LO = Lótico.

Table 1 - The studied areas in the Espinhaço Range (Minas Gerais State, Brazil) and their geographical information. $\mathrm{LE}=$ lentic; $\mathrm{LO}=$ lótico.

\begin{tabular}{|c|c|c|c|c|c|c|c|}
\hline Área & Bacia & Sub-bacia & $\begin{array}{l}\text { Coordenadas } \\
\text { geográficas }\end{array}$ & Município & Localidade & $\begin{array}{l}\text { Curso } \\
\text { de água }\end{array}$ & Ambiente \\
\hline $\begin{array}{l}\text { Lagoa } \\
\text { Americana }\end{array}$ & $\begin{array}{l}\text { Rio } \\
\text { Jequitinhonha }\end{array}$ & $\begin{array}{l}\text { Rio } \\
\text { Vacaria }\end{array}$ & $\begin{array}{l}42^{\circ} 19^{\prime} \mathrm{W} ; \\
16^{\circ} 16^{\prime} \mathrm{S}\end{array}$ & Grão Mogol & Vacaria & $\begin{array}{l}\text { Córrego } \\
\text { BraçoSeco }\end{array}$ & Açude (LE) \\
\hline $\begin{array}{l}\text { Lagoa } \\
\text { Arame }\end{array}$ & $\begin{array}{l}\text { Rio } \\
\text { São Francisco }\end{array}$ & $\begin{array}{l}\text { Rio das } \\
\text { Velhas }\end{array}$ & $\begin{array}{l}43^{\circ} 47^{\prime} \mathrm{W} ; \\
18^{\circ} 37^{\prime} \mathrm{S}\end{array}$ & $\begin{array}{l}\text { Conceição do } \\
\text { Mato Dentro }\end{array}$ & $\begin{array}{l}\text { Capitão } \\
\text { Felizardo }\end{array}$ & $\begin{array}{l}\text { Rio } \\
\text { Paraúna }\end{array}$ & $\begin{array}{l}\text { Lagoa } \\
\text { marginal (LE) }\end{array}$ \\
\hline $\begin{array}{l}\text { Lagoa } \\
\text { Comprida }\end{array}$ & $\begin{array}{l}\text { Rio } \\
\text { São Francisco }\end{array}$ & $\begin{array}{l}\text { Rio das } \\
\text { Velhas }\end{array}$ & $\begin{array}{l}43^{\circ} 35^{\prime} \mathrm{W} ; \\
19^{\circ} 23^{\prime} \mathrm{S}\end{array}$ & Jaboticatubas & $\begin{array}{l}\text { PARNA } \\
\text { Serra } \\
\text { do Cipó }\end{array}$ & $\begin{array}{l}\text { Rio } \\
\text { Nascente }\end{array}$ & $\begin{array}{l}\text { Lagoa } \\
\text { marginal (LE) }\end{array}$ \\
\hline $\begin{array}{l}\text { Lagoa } \\
\text { Estivinha }\end{array}$ & $\begin{array}{l}\text { Rio } \\
\text { Jequitinhonha }\end{array}$ & $\begin{array}{l}\text { Ribeirão } \\
\text { Vacaria }\end{array}$ & $\begin{array}{l}43^{\circ} 04^{\prime} \mathrm{W} ; \\
16^{\circ} 13^{\prime} \mathrm{S}\end{array}$ & $\begin{array}{l}\text { Riacho dos } \\
\text { Machados }\end{array}$ & Estivinha & $\begin{array}{l}\text { Ribeirão } \\
\text { Vacaria }\end{array}$ & Açude (LE) \\
\hline $\begin{array}{l}\text { Lagoa } \\
\text { Tanque } \\
\text { da Fazenda }\end{array}$ & Rio Doce & $\begin{array}{l}\text { Rio do } \\
\text { Carmo }\end{array}$ & $\begin{array}{l}43^{\circ} 29^{\prime} \mathrm{W} ; \\
20^{\circ} 18^{\prime} \mathrm{S}\end{array}$ & Mariana & $\begin{array}{l}\text { Antônio } \\
\text { Pereira }\end{array}$ & $\begin{array}{l}\text { Córrego } \\
\text { Mateus }\end{array}$ & $\begin{array}{l}\text { Lagoa } \\
\text { marginal (LE) }\end{array}$ \\
\hline $\begin{array}{l}\text { Rio } \\
\text { Corrento }\end{array}$ & $\begin{array}{l}\text { Rio } \\
\text { São Francisco }\end{array}$ & $\begin{array}{l}\text { Rio das } \\
\text { Velhas }\end{array}$ & $\begin{array}{l}44^{\circ} 24^{\prime} \mathrm{W} ; \\
17^{\circ} 43^{\prime} \mathrm{S}\end{array}$ & Lassance & $\begin{array}{l}\text { APA } \\
\text { Serra do } \\
\text { Cabral }\end{array}$ & $\begin{array}{l}\text { Rio } \\
\text { Corrento }\end{array}$ & Rio (LO) \\
\hline Rio Preto & $\begin{array}{l}\text { Rio } \\
\text { Jequitinhonha }\end{array}$ & $\begin{array}{l}\text { Rio } \\
\text { Araçuaí }\end{array}$ & $\begin{array}{l}49^{\circ} 19^{\prime} \mathrm{W} ; \\
8^{\circ} 05^{\prime} \mathrm{S}\end{array}$ & $\begin{array}{l}\text { São Gonçalo } \\
\text { do Rio Preto }\end{array}$ & $\begin{array}{l}\text { Parque } \\
\text { Estadual } \\
\text { Rio preto }\end{array}$ & Rio Preto & Rio (LO) \\
\hline $\begin{array}{l}\text { Rio } \\
\text { Taquaral }\end{array}$ & $\begin{array}{l}\text { Rio } \\
\text { Jequitinhonha }\end{array}$ & $\begin{array}{l}\text { Rio } \\
\text { Itacambiruçu }\end{array}$ & $\begin{array}{l}42^{\circ} 51^{\prime} \mathrm{W} ; \\
16^{\circ} 30^{\prime} \mathrm{S}\end{array}$ & Grão Mogol & $\begin{array}{l}\text { Parque } \\
\text { Estadual } \\
\text { Grão Mogol }\end{array}$ & $\begin{array}{l}\text { Rio } \\
\text { Taquaral }\end{array}$ & Rio (LO) \\
\hline
\end{tabular}

nitrogênio total e fósforo total. A matriz das macrófitas aquáticas foi construída pela presença e ausência, sendo utilizados os dados de Meyer \& Franceschinelli (2010) cujo levantamento florístico abrangeu o mesmo período da amostragem da água. Foram excluídas as espécies únicas, segundo recomendações de Causton (1988). As classificações das formas biológicas seguiram Pedralli (1990).

Foi empregada a análise de correspondência canônica (CCA) (ter Braak 1988) para analisar as correlações entre os aspectos físico-químicos da água e da vegetação. Foram testadas as significâncias das correlações entre as matrizes por meio do teste de Monte Carlo, identificando a probabilidade de acerto da relação encontrada entre as matrizes originais, utilizando-se o programa PC-ORD for Windows versão 4.14 (MacCune \& Mefford. 1999).

\section{Resultados}

As 70 espécies ocorrentes nas oito áreas de amostragem na Cadeia do Espinhaço (MG) (Tab. 2) são representadas por 26 famílias e 42 gêneros. A forma biológica mais frequente entre as espécies foi a anfíbia (39), seguida pela emergente (27). As espécies registradas como submersas fixas totalizaram sete e flutuante fixa foram três espécies.

Os resultados das variáveis físico-químicas da água para os rios estão apresentados na Tabela 3. O rio Preto apresentou o menor valor médio de $\mathrm{pH}$ dentre os rios estudados, sendo o menor valor verificado no período de março de 2002. Já os maiores valores médios de condutividade foram registrados para os rios Corrento e Preto. Entre os três ambientes lênticos foram encontradas médias similares para a variável OD, enquanto os valores de DBO 

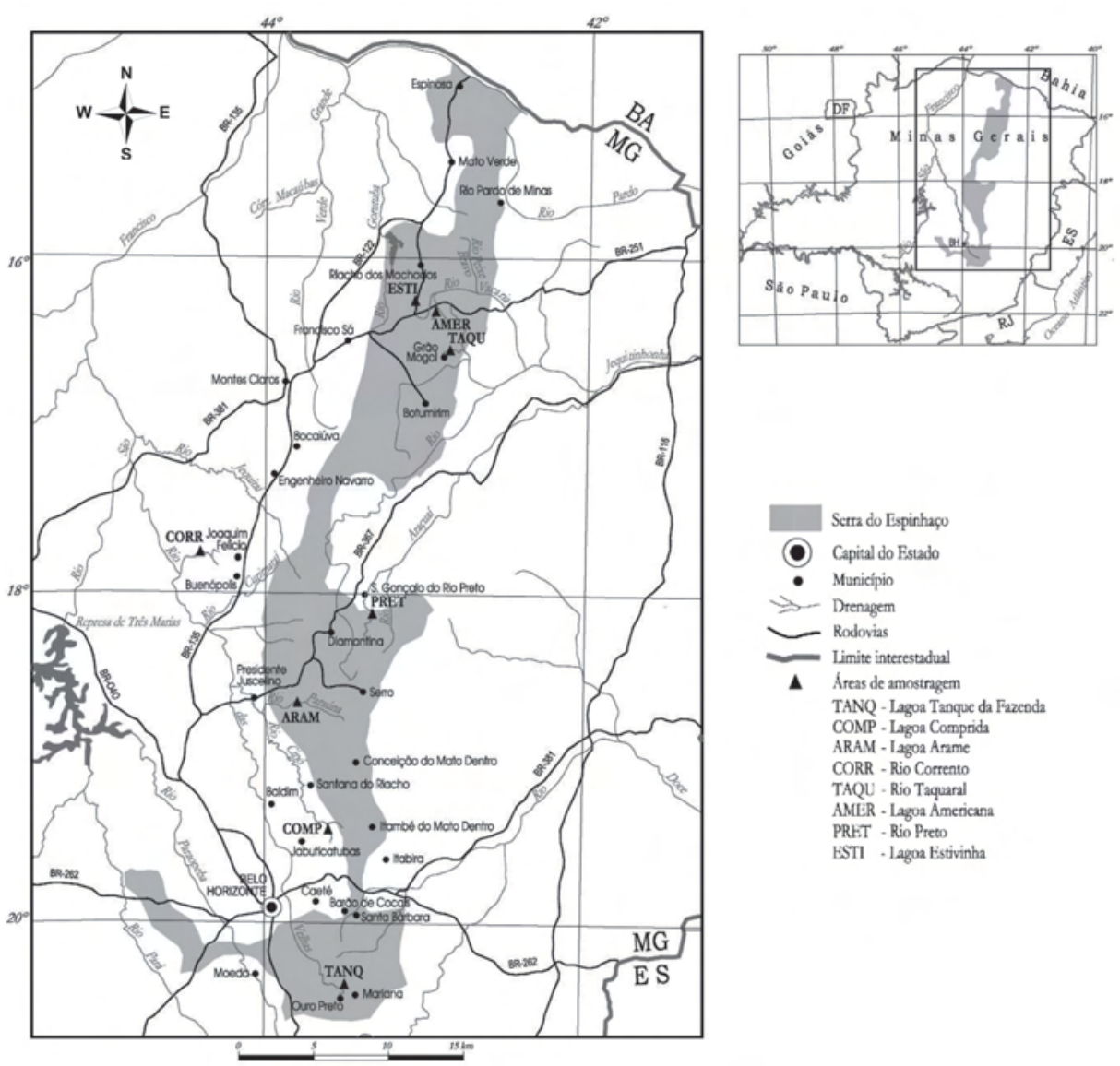

Figura 1 - Mapa de localização das áreas de amostragem das plantas vasculares associadas a áreas úmidas na Cadeia do Espinhaço (Minas Gerais, Brasil).

Figure 1 - Location map of the sampled areas of vascular plants associated with wetlands in the Espinhaço Range (Minas Gerais State, Brazil).

estiveram, em sua maioria, abaixo de $2,0 \mathrm{mg} / \mathrm{L}$. Em dezembro de 2001, foram registrados os maiores valores de DQO $(36,0 \mathrm{mg} / \mathrm{L})$ nos rios Taquaral e Preto. Os resultados para as concentrações de nutrientes nitrogenados e fosfatados foram similares entre as áreas e durante todo o período do estudo.

O maior valor de condutividade foi registrado para a lagoa Americana $(76 \mu \mathrm{S} / \mathrm{cm})$ e as maiores médias foram para Americana $(64 \mu \mathrm{S} / \mathrm{cm})$ e Estivinha ( $33 \mu \mathrm{S} / \mathrm{cm})$ (Tab.4). Da mesma forma, esses locais foram os responsáveis pelos maiores valores de DBO. Na lagoa Estivinha, também foram registradas as maiores médias das variáveis OD e pH. Os resultados para as concentrações de nutrientes nitrogenados e fosfatados variaram de 0,1 a 2,3 $\mathrm{mg} / \mathrm{L}$ e de 0,01 a 0,2 $\mathrm{mg} / \mathrm{L}$, respectivamente. As lagoas Americana e
Estivinha apresentaram os menores valores de transparência e o maior valor foi observado na lagoa Tanque da Fazenda.

Os resultados da análise de correspondência canônica das interações entre a presença das espécies vegetais nos oito ambientes e as variáveis físico-químicas da água estão apresentados na Figura 2 e Tabela 5. Os autovalores para os dois primeiros eixos de ordenação foram 0,623 (eixo1) e 0,390 (eixo 2). O eixo 1 teve $30,6 \%(\mathrm{p}=0,01)$ da variância explicada e foi positivamente correlacionado ao parâmetro oxigênio dissolvido e negativamente correlacionado às variáveis temperatura, $\mathrm{pH} \mathrm{e}$ nitrogênio total. O eixo 2 apresentou $19,1 \%(\mathrm{p}=0,01)$ da variância dos dados explicada e foi correlacionado negativamente com a condutividade, nitrogênio total e fósforo total. A variância explicada e acumulada pelos dois eixos correspondeu a $49,7 \%$. 
Tabela 2 - Famílias e espécies de plantas aquáticas na Cadeia do Espinhaço (estado de Minas Gerais, Brasil), com suas respectivas formas biológicas (A= anfíbia; E= emergente; FF= flutuante fixa; $\mathrm{SF}=$ submersa fixa) e áreas de ocorrência (Lagoa Americana - AMER; Lagoa Arame - ARAM; Lagoa Comprida - COMP; Lagoa Estivinha - ESTI; Lagoa Tanque da Fazenda - TANQ; Rio Corrento - CORR; Rio Preto - PRET; Rio Taquaral TAQU).

Table 2 - Families and species of aquatic plants in the Espinhaço Range (Minas Gerais State, Brazil), with their respective biological forms $(A=$ amphibious; E= emergent; FF= attached-floating; $\mathrm{SF}=$ submerged) and area of occurrence.

\begin{tabular}{|c|c|c|c|c|c|c|c|c|c|c|}
\hline Família & Espécie & FB & TANQ & COMP & ARAM & CORR & TAQU & AMER & PRET & ESTI \\
\hline \multirow[t]{2}{*}{ Alismataceae } & Echinodorus tenellus (Mart.) Buch. & $\mathrm{E}$ & & $\mathrm{X}$ & $X$ & & & $X$ & & \\
\hline & Sagittaria rhombifolia Cham. & $\mathrm{E}$ & & & $\mathrm{X}$ & & & $\mathrm{X}$ & & \\
\hline Araceae & Philodendron uliginosum Мауо & A & & & $\mathrm{X}$ & & & & $\mathrm{X}$ & \\
\hline Asteraceae & Eclipta prostrata (L.) L. & A & & & & & & $X$ & & $\mathrm{X}$ \\
\hline Cabombaceae & Cabomba furcata Schult. \& Schult.f. & $\mathrm{SF}$ & & $\mathrm{X}$ & & & & & & $\mathrm{X}$ \\
\hline \multirow[t]{18}{*}{ Cyperaceae } & Cyperus haspan $\mathrm{L}$. & A & $\mathrm{X}$ & $\mathrm{X}$ & $\mathrm{X}$ & & $\mathrm{X}$ & & & $\mathrm{X}$ \\
\hline & Cyperus lanceolatus Poir. & $\mathrm{E}$ & $\mathrm{X}$ & & $\mathrm{X}$ & & & & & \\
\hline & Cyperus luzulae (L.) Rottb. & A & & $\mathrm{X}$ & & & $\mathrm{X}$ & $\mathrm{X}$ & & $\mathrm{X}$ \\
\hline & Cyperus meyenianus Kunth & A & $\mathrm{X}$ & $\mathrm{X}$ & & $\mathrm{X}$ & $\mathrm{X}$ & & & \\
\hline & Cyperus prolixus Kunth & A & & $\mathrm{X}$ & & & $\mathrm{X}$ & & & \\
\hline & Cyperus virens Michx. & A & & & & & & $\mathrm{X}$ & & $\mathrm{X}$ \\
\hline & Eleocharis acutangula (Roxb.) Schult. & $\mathrm{E}$ & & & $\mathrm{X}$ & & & & & $\mathrm{X}$ \\
\hline & Eleocharis filiculmis Kunth & $\mathrm{E}$ & $\mathrm{X}$ & & & & $\mathrm{X}$ & & & \\
\hline & Eleocharis glauco-virens Boeck. & $\mathrm{E}$ & $\mathrm{X}$ & & & & $\mathrm{X}$ & & & \\
\hline & Eleocharis interstincta (Vahl) Roem. \& Schult. & $\mathrm{E}$ & & $\mathrm{X}$ & & & & $\mathrm{X}$ & & $\mathrm{X}$ \\
\hline & Eleocharis minima Kunth & $\mathrm{E} / \mathrm{SF} / \mathrm{A}$ & $\mathrm{X}$ & $\mathrm{X}$ & & & & & $\mathrm{X}$ & \\
\hline & Eleocharis montana (Kunth) Roem. \& Schult. & A & & & & & $\mathrm{X}$ & $\mathrm{X}$ & & \\
\hline & Eleocharis nana Kunth & $\mathrm{E}$ & & & & & $\mathrm{X}$ & $\mathrm{X}$ & $\mathrm{X}$ & \\
\hline & Eleocharis sellowiana Kunth & A & $\mathrm{X}$ & & $\mathrm{X}$ & & $\mathrm{X}$ & & & $\mathrm{X}$ \\
\hline & Fimbristylis autumnalis (L.) Roem. \& Schult. & $\mathrm{A} / \mathrm{E}$ & $\mathrm{X}$ & & & & $\mathrm{X}$ & & & \\
\hline & Fuirena umbellata Rottb. & A & & & & & $\mathrm{X}$ & $\mathrm{X}$ & & \\
\hline & Rhynchospora corymbosa (L.) Britton & A & $\mathrm{X}$ & & $\mathrm{X}$ & & $\mathrm{X}$ & $\mathrm{X}$ & & $\mathrm{X}$ \\
\hline & Rhynchospora marisculus Lindl. \& Nees & A & $\mathrm{X}$ & $\mathrm{X}$ & & & & & & \\
\hline \multirow[t]{3}{*}{ Eriocaulaceae } & Eriocaulon aquatile Koern. & SF & & & & $\mathrm{X}$ & & & $\mathrm{X}$ & \\
\hline & Leiothrix fluitans (Mart.) Ruhland & $\mathrm{E}$ & & & & $\mathrm{X}$ & & & $\mathrm{X}$ & \\
\hline & Syngonanthus caulescens (Poir.) Ruhland & $\mathrm{E}$ & $\mathrm{X}$ & & & $\mathrm{X}$ & & & & \\
\hline Hydrocharitaceae & Apalanthe granatensis (Humb. \& Bonpl.) Planch. & SF & & & & $\mathrm{X}$ & & $X$ & & \\
\hline Hypericaceae & Hypericum brasiliense Choisy & A & $\mathrm{X}$ & & $\mathrm{X}$ & & & & & \\
\hline Lamiaceae & Hyptis brevipes Poit. & A & & $\mathrm{X}$ & & & & $X$ & & $\mathrm{X}$ \\
\hline \multirow[t]{2}{*}{ Lentibulariaceae } & Utricularia breviscapa Wright ex Griseb. & $\mathrm{FF}$ & & $\mathrm{X}$ & & & & & & $\mathrm{X}$ \\
\hline & Utricularia gibba L. & $\mathrm{E}$ & $\mathrm{X}$ & $\mathrm{X}$ & $\mathrm{X}$ & & & $\mathrm{X}$ & & $\mathrm{X}$ \\
\hline
\end{tabular}




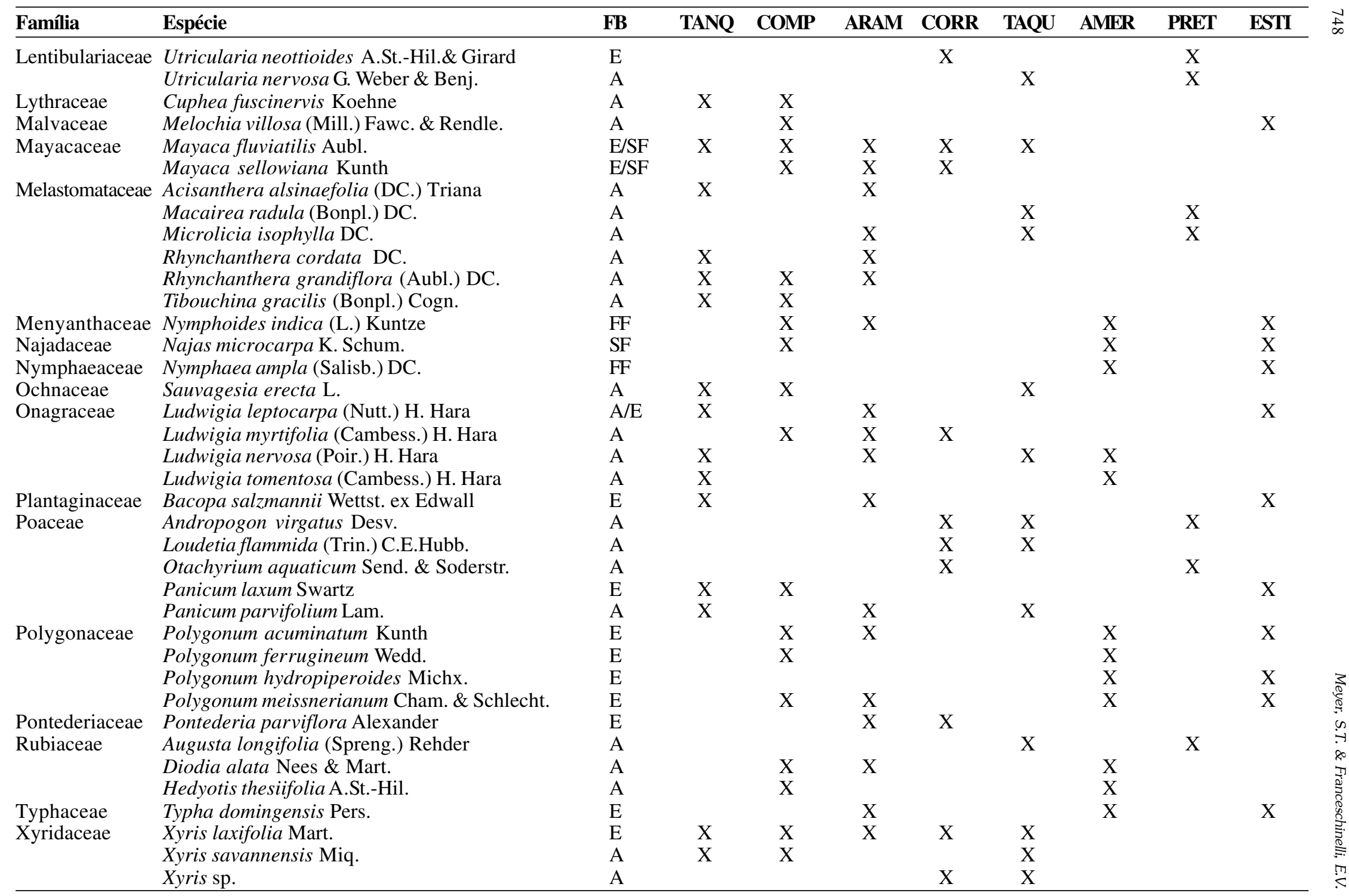


Tabela 3 - Variáveis físico-químicas da água nos ambientes lóticos amostrados na Cadeia do Espinhaço (MG). $\mathrm{OD}=$ oxigênio dissolvido, $\mathrm{DBO}=$ demanda biológica de oxigênio, $\mathrm{DQO}=$ demanda química de oxigênio, $\mathrm{N}$-amoniacal $=$ nitrogênio amoniacal, $\mathrm{N}$-total=nitrogênio total, $\mathrm{PRS}=$ fósforo reativo solúvel, $\mathrm{P}$-total= fósforo total.

Table 3 - Physicochemical water variables sampled in lotic environments sampled of the Espinhaço Range (Minas Gerais State, Brazil). DO = dissolved oxygen, BOD = biological oxygen demand, $\mathrm{COD}=$ chemical oxygen demand, ammonia- $\mathrm{N}=$ ammonium nitrogen, total $\mathrm{N}=$ total nitrogen, soluble reactive phosphorus $=\mathrm{PRS}$, total $\mathrm{P}=$ total phosphorus.

\begin{tabular}{|c|c|c|c|c|c|c|c|c|c|c|c|}
\hline Áreas & Coleta & $\begin{array}{c}\text { Temp. } \\
\left.\text { Água ( }{ }^{\circ} \mathrm{C}\right)\end{array}$ & pH & $\begin{array}{c}\text { Condutividade } \\
(\mu \mathrm{S} / \mathrm{cm})\end{array}$ & $\begin{array}{c}\mathrm{OD} \\
(\mathrm{mg} / \mathrm{L})\end{array}$ & $\begin{array}{c}\text { DBO } \\
(\mathrm{mg} / \mathrm{L})\end{array}$ & $\begin{array}{c}\text { DQO } \\
(\mathrm{mg} / \mathrm{L})\end{array}$ & $\begin{array}{c}\text { N-amon. } \\
(\mathrm{mg} / \mathrm{L})\end{array}$ & $\begin{array}{r}\text { N-total } \\
(\mathrm{mg} / \mathrm{L})\end{array}$ & $\begin{array}{l}\text { PRS } \\
(\mathrm{mg} / \mathrm{L})\end{array}$ & $\begin{array}{l}\text { P-total } \\
(\mathrm{mg} / \mathrm{L})\end{array}$ \\
\hline \multirow[t]{7}{*}{ Rio Corrento } & $\mathrm{dez} / 01$ & 29,0 & 5,7 & 7,9 & 7,0 & $<2,0$ & 17,0 & 0,1 & 0,3 & 0,04 & 0,06 \\
\hline & $\mathrm{mar} / 02$ & 26,0 & 4,9 & 5,5 & 7,0 & $<2,0$ & 28,0 & 0,3 & 0,5 & $<0,01$ & 0,02 \\
\hline & ago/02 & 23,5 & 4,9 & 7,2 & 8,0 & $<2,0$ & 13,0 & $<0,1$ & 0,7 & $<0,01$ & 0,02 \\
\hline & out $/ 02$ & 24,4 & 5,5 & 8,7 & 7,5 & 2,0 & 20,0 & 0,2 & 0,5 & $<0,01$ & 0,05 \\
\hline & $\mathrm{fev} / 03$ & 24,0 & 5,2 & 48,0 & 4,1 & $<2,0$ & 18,3 & 0,1 & 0,6 & $<0,01$ & 0,02 \\
\hline & jun/03 & 20,0 & 5,3 & 66,0 & 4,9 & 2,0 & 10,0 & 0,1 & 0,6 & $<0,01$ & 0,02 \\
\hline & $\mathrm{ago} / 03$ & 20,0 & 5,0 & 62,0 & 8,3 & $<2,0$ & 6,0 & $<0,1$ & 1,3 & $<0,01$ & 0,02 \\
\hline Média $\pm D P$ & & $23,8 \pm 3,1$ & $5,2 \pm 0,3$ & $29,3 \pm 28,0$ & $6,6 \pm 1,5$ & $1,93 \pm 0,05$ & $16,0 \pm 7,2$ & $0,14 \pm 0,08$ & $0,64 \pm 0,32$ & $0,01 \pm 0,01$ & $0,03 \pm 0,02$ \\
\hline \multirow[t]{7}{*}{ Rio Preto } & $\mathrm{dez} / 01$ & 26,6 & 4,2 & 8,5 & 6,7 & $<2,0$ & 36,0 & 0,1 & 0,6 & 0,01 & 0,04 \\
\hline & $\mathrm{mar} / 02$ & 24,0 & 4,0 & 10,5 & 7,6 & $<2,0$ & 25,0 & 0,2 & 0,6 & $<0,01$ & 0,01 \\
\hline & ago/02 & 23,0 & 4,3 & 18,9 & 8,0 & $<2,0$ & $<5,0$ & 0,09 & 0,1 & $<0,01$ & 0,01 \\
\hline & out $/ 02$ & 22,1 & 4,5 & 11,6 & 6,7 & $<2,0$ & 22,0 & 0,1 & 0,5 & $<0,01$ & 0,02 \\
\hline & $\mathrm{fev} / 03$ & 24,0 & 4,1 & 82,0 & 5,8 & $<2,0$ & 20,1 & 0,9 & 1,2 & $<0,01$ & 0,03 \\
\hline & jun/03 & 20,0 & 5,1 & 5,8 & 7,0 & $<2,0$ & $<5,0$ & 0,8 & 1,0 & $<0,01$ & 0,01 \\
\hline & ago/03 & 19,0 & 4,5 & 65,0 & 6,9 & $<2,0$ & $<5,0$ & 0,09 & 0,3 & $<0,01$ & 0,02 \\
\hline Média $\pm D P$ & & $22,6 \pm 2,5$ & $4,3 \pm 0,3$ & $28,9 \pm 31,1$ & $6,9 \pm 0,7$ & $1,9 \pm 0,0$ & $16,8 \pm 12,2$ & $0,32 \pm 0,36$ & $0,61 \pm 0,38$ & $0,009 \pm 0,0$ & $0,02 \pm 0,01$ \\
\hline \multirow[t]{7}{*}{ Rio Taquaral } & $\mathrm{dez} / 01$ & 25,7 & 5,0 & 14,1 & 6,5 & $<2,0$ & 36,0 & 0,1 & 0,6 & 0,01 & 0,04 \\
\hline & $\mathrm{mar} / 02$ & 31,0 & 5,2 & 9,4 & 6,7 & $<2,0$ & 33,0 & 0,7 & 0,8 & $<0,01$ & 0,02 \\
\hline & $\mathrm{ago} / 02$ & 22,0 & 5,2 & 8,6 & 8,0 & $<2,0$ & 7,0 & 0,09 & 0,3 & $<0,01$ & 0,02 \\
\hline & out $/ 02$ & 23,4 & 5,5 & 8,5 & 6,7 & $<2,0$ & 11,0 & 0,09 & 0,3 & 0,01 & 0,08 \\
\hline & $\mathrm{fev} / 03$ & 24,0 & 4,4 & 12,2 & 7,0 & $<2,0$ & 32,0 & 0,1 & 0,5 & $<0,01$ & 0,03 \\
\hline & jun/03 & 20,0 & 6,0 & 8,6 & 7,0 & $<2,0$ & 10,0 & 0,1 & 1,0 & $<0,01$ & 0,02 \\
\hline & ago/03 & 23,0 & 5,2 & 11,0 & 7,9 & $<2,0$ & 5,0 & 0,09 & 0,2 & $<0,01$ & 0,02 \\
\hline 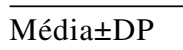 & & $24,1 \pm 3,4$ & $5,2 \pm 0,4$ & $10,3 \pm 2,1$ & $7,1 \pm 0,6$ & $1,9 \pm 0,0$ & $19,1 \pm 13,7$ & $0,18 \pm 0,2$ & $0,53 \pm 0,29$ & $0,009 \pm 0,0$ & $0,03 \pm 0,02$ \\
\hline
\end{tabular}

* Os valores indicados com o sinal < estão abaixo do limite de detecção dos equipamentos, sendo considerados para os cálculos das médias e desvio-padrão os valores imediatamente inferiores. N=7.

* Data are measured values for each parameter. For each collecting period is given mean and standard deviation ( $\mathrm{n}=7$ ). Values preceded by “<” were below the detection limit of the sensor equipment, and substituted by its immediately lower values (maintained the decimal cases) in order to calculate respective mean and standard deviation. 
Tabela 4 - Variáveis físico-químicas da água nos ambientes lênticos amostrados na Cadeia do Espinhaço (MG). $\mathrm{OD}=$ oxigênio dissolvido, $\mathrm{DBO}=$ demanda biológica de oxigênio, $\mathrm{DQO}=$ demanda química de oxigênio, $\mathrm{N}$-amoniacal= nitrogênio amoniacal, $\mathrm{N}$-total=nitrogênio total, $\mathrm{PRS}=$ fósforo reativo solúvel, $\mathrm{P}$-total= fósforo total.

Table 4 - Physicochemical water variables sampled in lentic environments of the Espinhaço Range (Minas Gerais State, $\mathrm{Brazil}$ ). $\mathrm{DO}=$ dissolved oxygen, $\mathrm{BOD}=$ biological oxygen demand, $\mathrm{COD}$ $=$ chemical oxygen demand, ammonia- $\mathrm{N}=$ ammonium nitrogen, total $\mathrm{N}=$ total nitrogen, soluble reactive phosphorus $=\mathrm{PRS}$, total $\mathrm{P}=$ total phosphorus .

\begin{tabular}{|c|c|c|c|c|c|c|c|c|c|c|c|c|}
\hline Áreas & Coleta & $\begin{array}{l}\text { Temp. } \\
\text { água }\left({ }^{\circ} \mathrm{C}\right)\end{array}$ & ) & $\begin{array}{l}\text { Transparência } \\
\text { (m) }\end{array}$ & $\begin{array}{l}\text { Condutividade } \\
\qquad(\mu \mathrm{S} / \mathrm{cm})\end{array}$ & $\begin{array}{c}\text { OD } \\
(\mathrm{mg} / \mathrm{L})\end{array}$ & $\begin{array}{c}\text { DBO } \\
(\mathrm{mg} / \mathrm{L})\end{array}$ & $\begin{array}{l}\text { DQO } \\
(\mathrm{mg} / \mathrm{L})\end{array}$ & $\begin{array}{c}\text { N-amon. } \\
(\mathrm{mg} / \mathrm{L})\end{array}$ & $\begin{array}{c}\text { N - total } \\
(\mathrm{mg} / \mathrm{L})\end{array}$ & $\begin{array}{c}\text { PRS } \\
(\mathrm{mg} / \mathrm{L})\end{array}$ & $\begin{array}{l}\text { P-total } \\
(\mathrm{mg} / \mathrm{L})\end{array}$ \\
\hline Lagoa & dez/01 & 28,0 & 7,4 & - & 57,2 & 8,0 & 4,0 & 49,0 & 0,8 & 1,6 & 0,02 & 0,06 \\
\hline \multirow[t]{6}{*}{ Americana } & mar/02 & 31,0 & 6,2 & 0,5 & 55,5 & 4,6 & 4,0 & 61,0 & 0,2 & 0,7 & $<0,01$ & 0,02 \\
\hline & ago/02 & 22,0 & 6,2 & 1,2 & 63,6 & 7,0 & 4,0 & 44,0 & 0,4 & 1,9 & $<0,01$ & 0,2 \\
\hline & out/02 & 26,4 & 7,1 & - & 64,0 & 6,7 & 4,0 & 43,0 & 1,5 & 2,3 & $<0,01$ & 0,06 \\
\hline & fev/03 & 27,0 & 6,2 & 1,0 & 60,5 & 4,5 & 3,0 & 36,3 & 0,9 & 1,8 & $<0,01$ & 0,05 \\
\hline & jun/03 & 23,0 & 5,8 & 1,0 & 71,7 & 6,4 & 2,0 & 31,0 & 1,1 & 2,0 & $<0,01$ & 0,04 \\
\hline & ago/03 & 20,0 & 6,3 & 1,0 & 76,0 & 4,8 & 2,0 & 56,0 & 0,6 & 1,5 & 0,01 & 0,04 \\
\hline$\underline{\text { Média } \pm D P}$ & \multicolumn{2}{|c|}{$25,3 \pm 3,8$} & $6,4 \pm 0,5$ & $0,9 \pm 0,2$ & $64,0 \pm 7,4$ & $6,0 \pm 1,3$ & $3,2 \pm 0,9$ & $45,7 \pm 10,5$ & $0,7 \pm 0,4$ & $1,6 \pm 0,5$ & $0,01 \pm 0,0$ & $0,06 \pm 0,06$ \\
\hline Lagoa & $\operatorname{dez} / 01$ & 25,7 & 6,4 & - & 21,7 & 5,8 & $<2,0$ & 36,0 & 0,1 & 0,6 & 0,01 & 0,04 \\
\hline \multirow[t]{6}{*}{ Arame } & mar/02 & 24,0 & 5,3 & 0,5 & 21,8 & 5,3 & 2,0 & 12,0 & $<0,1$ & 0,1 & $<0,01$ & 0,03 \\
\hline & ago/02 & 22,0 & 5,4 & 2,0 & 6,2 & 7,0 & $<2,0$ & 9,0 & $<0,1$ & 1,9 & $<0,01$ & 0,01 \\
\hline & out/02 & 29,1 & 5,8 & 2,0 & 20,9 & 6,4 & 2,0 & 12,0 & $<0,1$ & 0,4 & $<0,01$ & 0,02 \\
\hline & fev/03 & 29,0 & 5,7 & 0,5 & 20,7 & 5,6 & $<2,0$ & 9,3 & 0,1 & 0,4 & $<0,01$ & 0,05 \\
\hline & jun/03 & 23,0 & 5,1 & 0,4 & 5,8 & 7,0 & $<2,0$ & $<5,0$ & 0,8 & 1,0 & $<0,01$ & 0,01 \\
\hline & ago/03 & 18,0 & 4,7 & 2,9 & 17,7 & 6,9 & $<2,0$ & $<5,0$ & 0,5 & 0,9 & $<0,01$ & 0,02 \\
\hline$\underline{\text { Média } \pm D P}$ & \multicolumn{2}{|c|}{$24,4 \pm 3,9$} & $5,4 \pm 0,5$ & $1,3 \pm 1,0$ & $16,4 \pm 7,2$ & $6,2 \pm 0,7$ & $1,9 \pm 0,04$ & $12,5 \pm 10,7$ & $0,25 \pm 0,28$ & $0,7 \pm 0,6$ & $0,09 \pm 0,0$ & $0,02 \pm 0,01$ \\
\hline Lagoa & $\operatorname{dez} / 01$ & 26,4 & 5,7 & - & 8,8 & 6,5 & 4,0 & 25,0 & 0,1 & 0,2 & 0,01 & 0,01 \\
\hline \multirow[t]{6}{*}{ Comprida } & mar/02 & 27,5 & 4,8 & 1,0 & 5,5 & 7,2 & $<2,0$ & 32,0 & 0,1 & 0,4 & $<0,01$ & 0,02 \\
\hline & ago/02 & 24,0 & 4,9 & 1,0 & 19,5 & 6,0 & $<2,0$ & 38,0 & $<0,1$ & 0,8 & $<0,01$ & 0,02 \\
\hline & out/02 & 19,7 & 5,5 & 1,0 & 7,1 & 5,9 & 2,0 & 18,0 & 1,2 & 2,0 & 0,01 & 0,03 \\
\hline & fev/03 & 29,0 & 6,3 & 1,5 & 6,1 & 6,2 & $<2,0$ & 18,9 & 0,2 & 0,9 & $<0,01$ & 0,02 \\
\hline & jun/03 & 26,0 & 4,7 & 2,5 & 8,6 & 6,0 & $<2,0$ & 14,0 & 0,1 & 0,5 & 0,01 & 0,02 \\
\hline & ago/03 & 23,0 & 4,4 & 1,9 & 6,0 & 6,4 & $<2,0$ & 21,0 & $<0,1$ & 0,4 & $<0,01$ & 0,02 \\
\hline
\end{tabular}




\begin{tabular}{|c|c|c|c|c|c|c|c|c|c|c|c|c|}
\hline Áreas & Coleta & $\begin{array}{l}\text { Temp. } \\
\text { água }\left({ }^{\circ} \mathrm{C}\right)\end{array}$ & $\mathbf{p H}$ & $\begin{array}{c}\text { Transparência } \\
\text { (m) }\end{array}$ & $\begin{array}{c}\text { Condutividade } \\
(\mu \mathrm{S} / \mathrm{cm})\end{array}$ & $\begin{array}{l}\text { OD } \\
(\mathrm{mg} / \mathrm{L})\end{array}$ & $\begin{array}{c}\text { DBO } \\
(\mathrm{mg} / \mathrm{L})\end{array}$ & $\begin{array}{l}\text { DQO } \\
(\mathrm{mg} / \mathrm{L}) \\
\end{array}$ & $\begin{array}{c}\text { N-amon. } \\
(\mathrm{mg} / \mathrm{L})\end{array}$ & $\begin{array}{c}\mathbf{N}-\text { total } \\
(\mathrm{mg} / \mathrm{L})\end{array}$ & $\begin{array}{c}\text { PRS } \\
(\mathrm{mg} / \mathrm{L}) \\
\end{array}$ & $\begin{array}{c}\text { P-total } \\
(\mathrm{mg} / \mathrm{L})\end{array}$ \\
\hline Lagoa & $\mathrm{dez} / 01$ & 27,5 & 6,6 & - & 39,2 & 6,3 & 4,0 & 31,0 & 0,2 & 0,9 & 0,02 & 0,03 \\
\hline \multirow[t]{2}{*}{ Estivinha } & $\operatorname{mar} / 02$ & 31,0 & 6,3 & 1,0 & 21,9 & 6,3 & 3,0 & 21,0 & 0,2 & 0,7 & $<0,01$ & 0,02 \\
\hline & ago/02 & 23,0 & 6,9 & 0,4 & 28,1 & 12 & 4,0 & 29,0 & 0,1 & 0,8 & $<0,01$ & 0,02 \\
\hline Lagoa & $\mathrm{fev} / 03$ & 27,0 & 6,0 & 0,5 & 33,0 & 5,6 & 4,0 & 41,3 & $<0,1$ & 0,5 & $<0,01$ & 0,06 \\
\hline \multirow[t]{2}{*}{ Estivinha } & jun/03 & 27,0 & 8,0 & 1,1 & 35,1 & 9,1 & 1,9 & 23,0 & 0,1 & 0,6 & 0,01 & 0,02 \\
\hline & ago/03 & 21,0 & 6,9 & 0,9 & 35,0 & 4,9 & 1,9 & 33,0 & 0,1 & 0,8 & $<0,01$ & 0,02 \\
\hline Média $\pm D P$ & & $26,6 \pm 3,5$ & $7,0 \pm 0,9$ & $0,7 \pm 0,3$ & $33,5 \pm 6,7$ & $7,3 \pm 2,4$ & $3,4 \pm 1,1$ & $31,1 \pm 7,7$ & $0,1 \pm 0,07$ & $0,7 \pm 0,2$ & $0,01 \pm 0,0$ & $0,03 \pm 0,01$ \\
\hline Lagoa & $\mathrm{dez} / 01$ & 28,1 & 6,4 & - & 5,3 & 7,5 & $<2,0$ & 12,0 & 0,3 & 0,5 & 0,01 & 0,01 \\
\hline \multirow{2}{*}{ Tanque } & jun/03 & 26,0 & 6,0 & 1,5 & 12,5 & 7,0 & $<2,0$ & $<5,0$ & 0,1 & 0,3 & $<0,01$ & 0,04 \\
\hline & ago/03 & 20,0 & 4,8 & 4,5 & 8,6 & 6,9 & $<2,0$ & $<5,0$ & 0,4 & 0,6 & $<0,01$ & 0,01 \\
\hline Média $\pm D P$ & & $24,5 \pm 2,9$ & $5,7 \pm 0,6$ & $3,5 \pm 1,5$ & $7,8 \pm 2,8$ & $6,7 \pm 0,7$ & $1,9 \pm 0,0$ & $9,6 \pm 6,3$ & $0,3 \pm 0,4$ & $0,6 \pm 0,3$ & $0,009 \pm 0,0$ & $0,02 \pm 0,01$ \\
\hline
\end{tabular}

* Os valores indicados com o sinal < estão abaixo do limite de detecção dos equipamentos, sendo considerados para os cálculos das médias e desvio-padrão os valores imediatamente inferiores. N=7.

* Data are measured values for each parameter. For each collecting period is given mean and standard deviation ( $\mathrm{n}=7$ ). Values preceded by “ “" were below the detection limit of the sensor equipment, and substituted by its immediately lower values (maintained the decimal cases) in order to calculate respective mean and standard deviation. 
Tabela 5 - Análise de correspondência canônica entre as espécies e as variáveis físico-químicas da água em áreas úmidas na Cadeia do Espinhaço ( $\mathrm{MG}$ ): matriz de correlações dos eixos e parâmetros físico-químicos da água, autovalores e porcentagem de variância explicada. Table 5 - Canonical correspondence analysis between species and physicochemical variables of water in wetlands in the Espinhaço Range (Minas Gerais State, Brazil): the correlation matrix of the axes and physicochemical, eigenvalues and percentage of variance explained.

\begin{tabular}{lcc}
\hline Variável & Eixo 1 & Eixo 2 \\
\hline Temperatura & $-0,878$ & $-0,075$ \\
pH & $-0,770$ & $-0,247$ \\
Condutividade & $-0,309$ & $-0,744$ \\
OD & 0,415 & 0,194 \\
DQO & $-0,180$ & $-0,490$ \\
N-Total & $-0,452$ & $-0,573$ \\
P-Total & $-0,281$ & $-0,573$ \\
Autovalor & 0,623 & 0,390 \\
\% variância explicada & 30,6 & 19,1 \\
\% variância explicada (acumulativa) & 30,6 & 49,7 \\
\hline
\end{tabular}

A ordenação das áreas no primeiro eixo separou o conjunto de áreas de ambiente lêntico Estivinha, Americana e Comprida, concentrandose no lado esquerdo, e em oposição os rios (ambientes lóticos) Corrento e Preto. As mais fortes correlações tenderam da esquerda para a direita para uma diminuição de temperatura, do pH (águas mais ácidas) e dos teores de nitrogênio. O rio Taquaral tendeu a uma maior disponibilidade de oxigênio em oposição a lagoa Americana. Com relação ao segundo eixo, observa-se no extremo superior a lagoa Tanque da Fazenda e no inferior as lagoas Americana, Estivinha e o rio Preto. Isto sugere maiores valores de condutividade para a lagoa Americana e o rio Preto e especificamente maiores teores de DQO para lagoa Americana. Em oposição, para a lagoa Tanque da Fazenda é sugerido um ambiente com menores valores de condutividade e DQO.

A ordenação das espécies (Fig. 2) sugere que Cabomba furcata, Utricularia breviscapa, Polygonum acuminatum e Nymphoides indica tendem a ocorrer em ambientes de maior temperatura e $\mathrm{pH}$ mais neutro. Typha domingensis, Eleocharis interstincta, Hedyotis thesiifolia, Polygonum hydropiperoides, Polygonum ferrugineum, Najas microcarpa e Nymphaea ampla tendem a ocorrer em ambientes de maior concentração de nitrogênio total e fósforo. No outro extremo, concentram-se as espécies como Ludwigia myrtifolia, Mayaca fluviatilis, Xyris laxifolia, Syngonanthus caulescens e Eleocharis minima sugerindo a preferência por ambiente de maior oxigenação.

Os resultados da análise de correspondência canônica para as formas biológicas e as variáveis físico-químicas estão apresentados na Figura 3 e Tabela 6. Os autovalores para os dois primeiros eixos de ordenação foram 0,069 (eixo 1) e 0,039 (eixo 2). Os autovalores são considerados baixos, indicando gradientes curtos, ou seja, a maioria das espécies está distribuída por todo o gradiente (ter Braak 1995). O primeiro eixo teve $57,6 \%(\mathrm{p}=0,01)$ da variância explicada e foi mais fortemente correlacionado à temperatura, condutividade, nitrogênio total e pH. Exclusivamente, esse eixo foi correlacionado positivamente com o oxigênio dissolvido. O segundo eixo apresentou $32,3 \%$ $(\mathrm{p}=0,02)$ da variância explicada dos dados e foi mais fortemente correlacionado com a temperatura. A variância explicada e acumulada pelos dois eixos correspondeu a $89,9 \%$.

A ordenação das formas biológicas sugeriu uma correlação negativa da forma flutuante fixa com o primeiro eixo, sendo as correlações relacionadas ao aumento da temperatura e maior disponibilidade de nitrogênio e condutividade. A forma submersa fixa apresentou maior correlação com o segundo eixo. A ordenação das formas anfíbia e emergente sugere que elas podem ser indiferentes às variáveis físico-químicas avaliadas ou ainda podem ocorrer em ambientes de características intermediárias.

\section{Discussão}

No rio Preto, foi detectado o maior valor de condutividade elétrica $(82 \mathrm{mS} / \mathrm{cm})$ e os menores valores de $\mathrm{pH}$ entre os rios estudados. Em geral, considera-se que quanto maior a poluição, maior a condutividade em função do aumento do conteúdo mineral (Brigante et al. 2003). Entretanto, segundo Esteves (1998b), corpos de água ricos em compostos húmicos e com baixos valores de $\mathrm{pH}$ podem apresentar altos valores de condutividade, em função da decomposição do material alóctone. Este fato é devido a grande quantidade de material em decomposição que é carreado para esses ambientes advindos da bacia de drenagem. Os baixos valores de $\mathrm{pH}$ são devidos ao intenso processo de decomposição, caracterizado pela alta DQO, e consequente liberação de ácidos orgânicos 


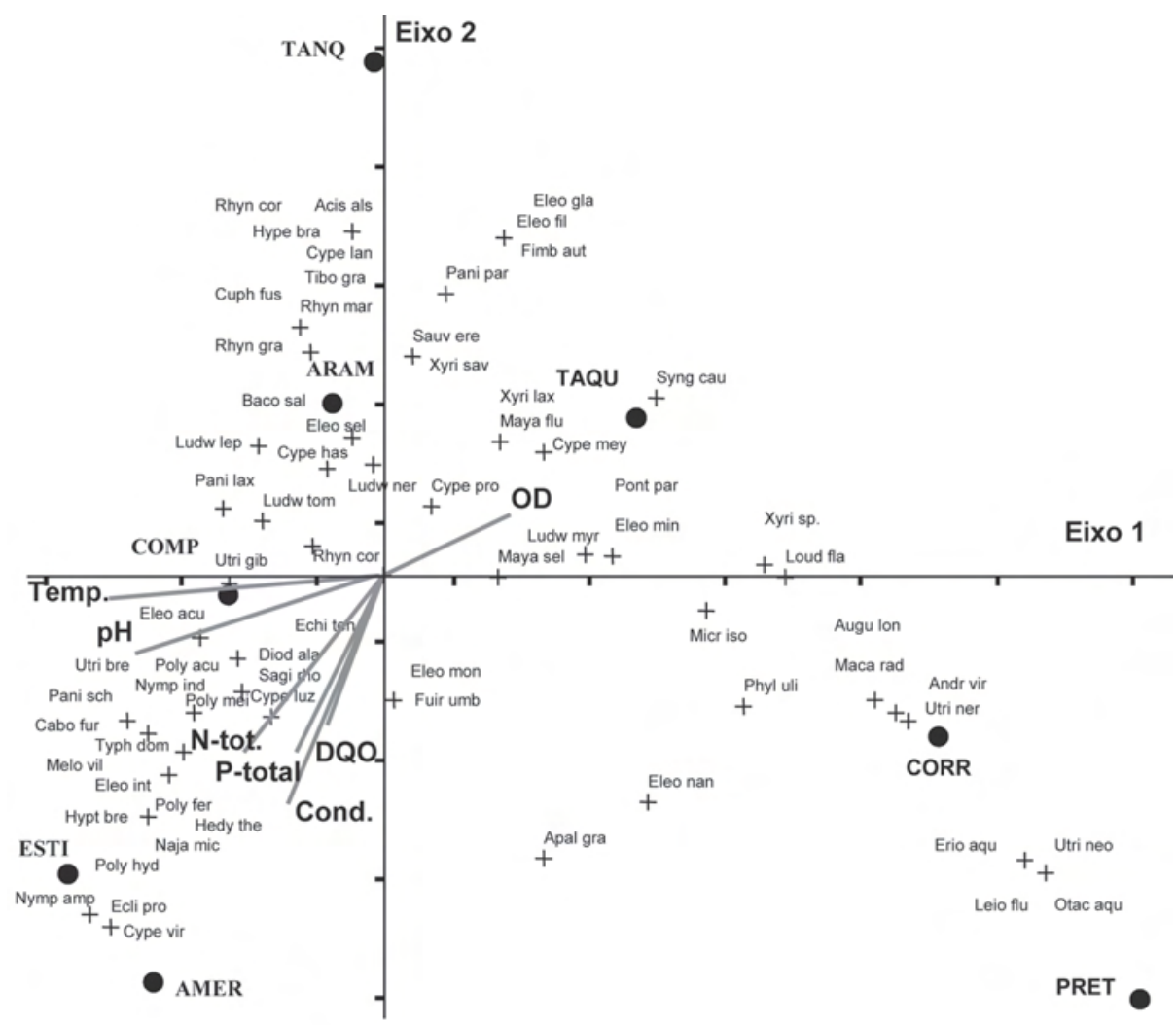

Figura 2 - Diagrama de ordenação produzido pela análise de correspondência canônica (CCA) da ocorrência de 70 espécies amostradas em oito áreas úmidas na Cadeia do Espinhaço (MG). O diagrama mostra a distribuição das espécies nos dois primeiros eixos de ordenação. As linhas contínuas indicam grandeza e o sentido do aumento das variáveis ambientais. As esferas indicam as áreas de amostragem: Lagoa Americana - AMER; Lagoa Arame - ARAM; Lagoa Comprida - COMP; Lagoa Estivinha - ESTI (lênticos); Lagoa Tanque da Fazenda - TANQ; Rio Corrento - CORR; Rio Preto-PRET; Rio Taquaral TAQU (lóticos); Acis als $=$ Acisanthera alsinaefolia $;$ Andr vir $=$ Andropogon virgatus; Apal gra $=$ Apalanthe granatensis; Augu lon $=$ Augustalongifolia $;$ Baco $\mathrm{sal}=$ Bacopa salzmanniï; Cabo fur $=$ Cabomba furcata $;$ Cuph fus $=$ Cuphea fuscinervis $;$ Cype has $=$ Cyperus haspan; Cype lan $=C$. lanceolatus $;$ Cype luz $=C$. luzulae $;$ Cype mey $=C$. meyenianus $;$ Cype pro $=C$. prolixus $;$ Cype vir $=C$. virens $;$ Diodala $=$ Diodia alata; Echi ten $=$ Echinodorus tenellus; Ecli pro $=$ Eclipta prostrata $;$ Eleo açu $=$ Eleocharis acutangula $;$ Eleo fil $=$ E. filiculmis; Eleo gla $=$ E. glauco-virens; Eleo int $=E$. interstincta; Eleo min $=E$. minima; Eleo mon $=E$. montana; Eleo nan $=E$. nana; Eleo sel $=E$. sellowian $;$; Erio aqu $=$ Eriocaulon aquatile $;$ Fimb aut $=$ Fimbristylis autumnalis; $;$ Fuir umb $=$ Fuirena umbellata $;$ Hedy the $=$ Hedyotis thesiifolia; Hype bra = Hypericumbrasiliense; Hyptbre=Hyptis brevipes; Leio flu $=$ Leiothrix fluitans; Loud fla = Loudetiaflammida; Ludw lep $=$ Ludwigia leptocarpa $;$ Ludw myr $=L$. myrtifolia $;$ Ludw ner $=$ L. nervos $a ;$ Ludw tom $=L$. tomentosa $;$ Maca rad $=$ Macairea radula $;$ Maya flu=Mayacafluviatilis; Maya sel=M. sellowiana; Melo vil=Melochia villos $;$; Micr iso=Microlicia isophylla; Naja mic $=$ Najas microcarpa $;$ Nymp amp $=$ Nymphaea ampla $;$ Nymp ind $=$ Nymphoides indica $;$ Otac aqu $=$ Otachyrium aquaticum $;$ Pani lax = Panicum laxum; Pani sch $=$ P. schwackeanum $;$ Pani par $=$ P. parvifolium; Phyl uli = Philodendron uliginosum; Poly acu $=$ Polygonum acuminatum; Poly fer $=P$. ferrugineum $;$ Poly hyd $=$ P. hydropiperoides; Poly mei $=$ P. meissnerianum $;$ Pont par $=$ Pontederia parviflora $;$ Rhyn cor $=$ Rhynchanthera cordata, Rhyn gra $=R$. grandiflora $;$ Rhyn cor $=R$. corymbosa $;$ Rhyn mar $=R$. marisculus; Sagi rho $=$ Sagittaria rhombifolia $;$ Sauv ere $=$ Sauvagesia erecta; Syng cau $=$ Syngonanthus caulescens; Tibo gra $=$ Tibouchina gracilis; Typh dom $=$ Typha domingensi; Utri bre $=$ Utricularia breviscap $;$; Utri gib $=U$. gibba $;$ Utrineo $=U$. neottioides; Utri ner $=U$. nervos $;$;yri lax $=$ Xyris laxifolia $;$ Xyri sav $=X$. savannensis; Xyri sp. $=X$. sp. Cond $=$ condutividade elétrica; $\mathrm{OD}=$ oxigênio dissolvido; $\mathrm{DBO}=$ demanda bioquímica de oxigênio; $\mathrm{DQO}=$ demanda química de oxigênio; $\mathrm{N}$-total = nitrogênio total e Ptotal $=$ fósforo total.

Figure 2 - Ordination diagram produced by canonical correspondence analysis (CCA) of the occurrence of 70 species in eight wetlands in the Espinhaço Range (Minas Gerais State, Brazil). The diagram shows the distribution of species in the first two ordination axes. Solid lines indicate magnitude and direction of increased environmental variables. The spheres indicate the sampling areas. 
dissolvidos, sendo que nesses ambientes a água pode adquirir um tom amarronzado (Esteves 1998b). Esta situação foi verificada nos rios estudados e principalmente no rio Preto, onde as águas apresentaram coloração escura (cor de chá) e, com frequiência, observou-se grande quantidade de material alóctone, como folhas, frutos, sementes e galhos, no leito do rio.

Nos ambientes lóticos amostrados, os valores de condutividade elétrica refletiram o aporte de nutrientes naturais da decomposição do material alóctone. No entanto, particularmente no rio Corrento, foram registrados valores mais elevados de condutividade que coincidiram com o surgimento de interferências antrópicas. Os valores de DBO para os três ambientes foram inferiores ao limite de detecção do método analítico e estão de acordo com o estabelecidos para a Classe I (COPAM; CERH-MG 2008), que enquadra os corpos de água doce considerando seu nível de qualidade. A classe I é indicada para a proteção das comunidades aquáticas, entre outros usos.

Todos os ambientes lóticos apresentaram boas taxas de oxigênio dissolvido. Esta característica pode estar associada à movimentação das águas existentes nos trechos amostrados. Os fluxos de água mais intensos verificados em áreas de corredeiras proporcionam maior disponibilidade de gases como oxigênio e dióxido de carbono dissolvidos (Haslam 1978). A agitação da superfície da água acelera a troca de gases, mesmo em ambientes com suaves movimentações, e aumenta muito em locais de corredeiras ou quedas d'água (Sculthorpe 1967). Em função deste fato, não há um comprometimento dos níveis de oxigênio na água, apesar da elevada demanda química verificada.

$\mathrm{O}$ fósforo presente nas águas naturais pode ser originado a partir da dissolução de rochas da bacia de drenagem, do material particulado da atmosfera, da decomposição de organismos alóctones ou ainda da descarga de esgotos e deflúvio superficial agrícola (Brigante et al. 2003). Provavelmente, os valores de fósforo total verificados nos ecossistemas lóticos da Cadeia do Espinhaço sejam de origem natural, pois a porção do fósforo que é utilizada pelas comunidades biológicas, representada pelo fósforo reativo solúvel (PRS), foi registrada em baixas concentrações. As formas mais importantes do nitrogênio presente nos ambientes aquáticos são o nitrato e o íon amônio, pois representam as principais fontes de nitrogênio para os produtores primários (Esteves 1998b). As concentrações de nitrogênio amoniacal e nitrogênio

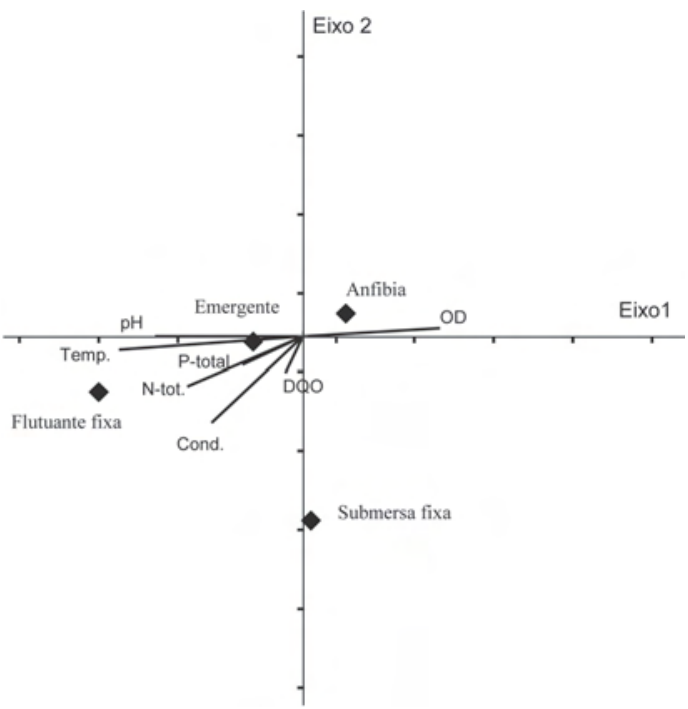

Figura 3 - Diagrama de ordenação produzido pela análise de correspondência canônica (CCA) da abundância de quatro formas biológicas ocorrentes em oito áreas úmidas na Cadeia do Espinhaço (MG). O diagrama mostra a distribuição das formas biológicas nos dois primeiros eixos de ordenação. As linhas contínuas indicam grandeza e o sentido do aumento das variáveis ambientais. Cond $=$ condutividade elétrica; $\mathrm{OD}=$ oxigênio dissolvido; $\mathrm{DBO}=$ demanda bioquímica de oxigênio; $\mathrm{DQO}=$ demanda química de oxigênio; $\mathrm{N}$-total $=$ nitrogênio total e P- total $=$ fósforo total.

Figure 3 - Ordination diagram produced by canonical correspondence analysis (CCA) of abundance of four biological forms occurring in eight wetlands in the Espinhaço Range (Minas Gerais State, Brazil). The diagram shows the distribution of biological forms in the first two ordination axes. Solid lines indicate magnitude and direction of increased environmental variables. Cond = electrical conductivity; $\mathrm{OD}=$ dissolved oxygen; $\mathrm{DBO}=$ oxygen biochemical demand; $\mathrm{DQO}=$ oxygen chemical demand; $\mathrm{N}$-total $=$ total nitrogen and $\mathrm{P}-$ total $=$ total phosphate.

total foram consideradas baixas para os três ambientes lóticos estudados, pois não ocorreram nestes trechos grandes densidades de comunidades fitoplanctônicas e macrófitas aquáticas, característica de ambientes ricos em nutrientes.

Comparando-se os ambientes lênticos, verifica-se que os maiores valores de condutividade elétrica e DQO foram associados aos açudes (lagoas Americana e Estivinha). Na lagoa Americana, foi registrado o maior valor médio e as maiores concentrações de nutrientes fosfatados e nitrogenados. Entretanto, segundo Esteves (1998b), os íons nitrato, nitrito e especialmente o ortofosfato têm pouca influência nessa variável e o íon amônio pode ter influência quando em altas concentrações, 
Tabela 6 - Análise de correspondência canônica entre as formas biológicas e as variáveis físico-químicas da água em áreas úmidas na Cadeia do Espinhaço ( $\mathrm{MG})$ : matriz de correlações dos eixos e parâmetros físicoquímicos da água, autovalores e porcentagem de variância explicada.

Table 6-Canonical correspondence analysis between biological forms and the physicochemical variables of water in wetlands in the Espinhaço Range (Minas Gerais State, Brazil): the correlation matrix of the axes and physicochemical, eigenvalues and percentage of variance explained.

\begin{tabular}{lcc}
\hline Variável & Eixo 1 & Eixo 2 \\
\hline Temperatura & $-0,641$ & 0,434 \\
pH & $-0,490$ & 0,395 \\
Condutividade & $-0,524$ & $-0,099$ \\
OD & 0,479 & $-0,324$ \\
DQO & $-0,150$ & $-0,100$ \\
N-Total & $-0,509$ & 0,108 \\
P-Total & $-0,271$ & 0,050 \\
Scores & & \\
Anfíbia & 0,203 & $-0,016$ \\
Emergente & -0.178 & 0,110 \\
Flutuante fixa & $-0,819$ & 0,320 \\
Submersa fixa & $-0,446$ & $-0,759$ \\
Autovalor & 0,069 & 0,039 \\
\% variância explicada & 57,6 & 32,3 \\
\% variância explicada (acumulativa) & 57,6 & 89,9 \\
\hline
\end{tabular}

o que não ocorreu na lagoa Americana. Nas regiões tropicais, os valores de condutividade estão mais relacionados com a sazonalidade e com as características geoquímicas da região, do que com o estado trófico, como acontece em regiões temperadas (Esteves 1998b). Desta forma, apesar da evidência de valores superiores de condutividade nos ambientes lênticos artificiais, estes não podem ser associados a maior eutrofização dos ambientes.

À exceção das lagoas Americana e Estivinha a demanda bioquímica de oxigênio não ultrapassou o valor estabelecido para a Classe I (COPAM; CERH-MG 2008). As concentrações de oxigênio dissolvido também estiveram dentro dos limites estabelecidos para a Classe I, com ligeiro declínio nos meses representativos do período chuvoso. As principais fontes de oxigênio para a água são a atmosfera, a fotossíntese (Esteves 1998b) e as movimentações, mesmo que suave, da superfície da água (Sculthorpe 1967). Observou-se maior variação das taxas de OD na lagoa Estivinha, onde foram registrados valores entre $4,1 \mathrm{mg} / \mathrm{Le} 12,0 \mathrm{mg} / \mathrm{L}$. Em lagos tropicais, principalmente rasos, a elevação do nível da água e o aumento da concentração de matéria orgânica são comuns nos períodos de maior concentração de chuvas. Em conseqüência desse acúmulo de matéria orgânica, há diminuição das taxa de fotossíntese em função da redução da transparência da água, ao mesmo tempo em que as elevadas temperaturas, freqüentes neste período, podem reduzir a solubilidade do oxigênio (Esteves 1998b). O menor valor de OD para a lagoa Estivinha foi registrado em época de maior concentração de chuvas na região. Provavelmente, esse fator pode ter contribuído para uma menor disponibilidade de oxigênio dissolvido. Contudo, no conjunto dos ambientes lênticos não houve comprometimento da disponibilidade de oxigênio, apesar da demanda química ser elevada.

As concentrações dos nutrientes fosfatados foram baixas durante o período de estudos nos ambientes lênticos. Os teores de fósforo reativo solúvel permaneceram em baixas concentrações e as concentrações de nitrogênio amoniacal e de nitrogênio total também foram baixas. Todas as lagoas do estudo apresentaram algum tipo de interferência antrópica sendo susceptíveis à elevação da concentração de nutrientes, mesmo a lagoa Comprida, localizada no Parque Nacional da Serra do Cipó, onde foram verificados impactos advindos de entrada clandestina de animais domésticos. Contudo, em função dos resultados obtidos, não foi possível verificar essa relação. Provavelmente, parte do fósforo presente nesses ambientes tem sua origem pela dissolução de rochas da bacia de drenagem. As lagoas Americana e Estivinha apresentaram os menores valores de transparência, em média, quando comparadas aos ambientes lênticos naturais. A maior média foi registrada para a lagoa Tanque da Fazenda, sendo observadas águas límpidas, mesmo em períodos de maior ocorrência de chuvas.

$\mathrm{Na}$ ordenação das espécies em relação aos dados ambientais foi observada maior concentração de espécies junto às lagoas Americana, Estivinha e Comprida, cujas correlações mais fortes foram a temperatura, o $\mathrm{pH}$ e o nitrogênio. Entre essas espécies podem ser citadas Eleocharis interstincta, Cabomba furcata, Najas microcarpa, Typha domingensis, Nymphoides indica, Polygonum hydropiperoides e Nymphaea ampla. A temperatura da água pode ter pouca influência sob a distribuição das espécies (Sculthorpe 1967), pois as plantas aquáticas possuem uma ampla faixa de tolerância à temperatura, podendo ser abundantes em climas temperados ou tropicais. Entretanto, cada espécie pode apresentar seu ótimo de temperatura (Camargo et al. 2003). Cabomba 
furcata, por exemplo, segundo estudo de Benassi et al. (2001), apresenta maior produtividade primária sob temperaturas mais elevadas. Existe uma intensa interdependência entre comunidades vegetais e os valores do $\mathrm{pH}$ do meio e as plantas podem interferir no $\mathrm{pH}$ do ambiente, assim como algumas espécies podem ter seu metabolismo alterado pela variação dele (Esteves 1998b). Segundo Pott \& Pott (2000), Najas microcarpa ocorre em águas ácidas ou neutras e Typha domingensis tolera $\mathrm{pH}$ entre 4,8 e 8,7.

A disponibilidade de nutrientes pode ser um fator limitante na produção primária de ecossistemas aquáticos (Esteves 1998b, Thomaz \& Bini 1999, Camargo et al. 2003). Por outro lado, algumas espécies podem estar ausentes nos ambientes ricos em nutrientes em função de seu limitado poder competitivo (Sculthorpe 1967). As espécies vegetais invasoras podem ser favorecidas neste sentido, pois colonizam ambientes alterados. Várias espécies aglomeradas junto às lagoas Americana e Estivinha são citadas como invasoras típicas de ambientes ricos em nutrientes: Typha domingensis, Nymphaea ampla, Eleocharis interstincta, Nymphoides indica e Polygonum hydropiperoides (Leitão-Filho et al. 1972, 1975; Bacchi et al. 1984; Brandão et al. 1989; Lorenzi 2000). Palma-Silva (1998) e Pott \& Pott (2000) discutiram que Typha domingensis pode ter sua população aumentada com perturbação por adubação e poluição por esgoto e Lorenzi (2000) citou Nymphaea ampla como sendo favorecida pelo aumento de nutrientes dissolvidos na água.

Determinadas formas biológicas também podem ser favorecidas por ambientes de maior disponibilidade de nutrientes. As plantas flutuantes são mais presentes em ambientes eutrofizados e as espécies aquáticas submersas têm sido associadas a ambientes oligotróficos (Camargo et al. 2003). De acordo com esses autores, em ambientes ricos em nutrientes pode existir proliferação do fitoplâncton e das plantas aquáticas flutuantes, diminuindo a disponibilidade de luz e inviabilizando a sobrevivência de espécies submersas. A ordenação das formas biológicas na análise multivariada sugeriu a presença de espécies flutuantes fixas nos ambientes mais ricos em nitrogênio. De acordo com Sculthorpe (1967), as plantas desse grupo podem absorver nutrientes não somente do substrato, mas também da coluna d' água. $\mathrm{O}$ resultado da ordenação para as demais formas biológicas sugeriu uma indiferença quanto às características físico-químicas da água. Para as plantas aquáticas enraizadas (emergentes e anfíbias), o sedimento constitui a principal fonte de nutrientes e as formas submersas podem absorver íons da água ou do substrato (Sculthorpe 1967, Camargo et al. 2003), mas, conforme discutido anteriormente, estão associadas a ambientes oligotróficos.

A interpretação de correlações entre a distribuição das espécies e as variáveis ambientais exige cautela, conforme explicitado por Botrel et al. (2002), pois muitas vezes a presença da espécie pode estar mais relacionada ao tipo de habitat ou substrato do que as características físico-químicas da água (Sculthorpe 1967). Neste sentido, provavelmente a polarização das espécies Ericaulon aquatile, Leiothrix fluitans e Utricularia neottioides junto aos rios Corrento e Preto está mais relacionadas às características físicas dos corpos d'água. Eriocaulon aquatile e Leiothrix fluitans ocorrem submersas em riachos (Cook 1996) e foram observadas colonizando corredeiras nos rios estudados, muitas vezes utilizando o substrato rochoso dos leitos para sua fixação. Segundo Fromm-Trinta (1996), Utricularia neottioides ocorre em ambientes rochosos, encachoeirados, ou poças d'água sobre rochas. Nos rios Corrento e Preto, essa espécie foi coletada nas corredeiras.

Merece ser destacada também a ocorrência de Eleocharis minima na lagoa Tanque da Fazenda. Segundo a análise multivariada, essa área pareceu diferir bastante das demais áreas; tanto com relação às características físico-químicas da água, quanto da composição florística. Apesar de E. minima ser sugerida como ocorrente em ambientes com maior oxigênio dissolvido, a sua presença provavelmente foi influenciada por outras características físicas do ambiente. Segundo Pott \& Pott (2000), essa espécie pode apresentar diferentes formas biológicas, em resposta às características do ecossistema, podendo assumir as formas submersa, emergente e anfíbia. Nas áreas em que ocorreu - rio Preto, lagoa Comprida e lagoa Tanque da Fazenda - apresentou essas três formas, sendo que dominou praticamente todo o espelho d'água na lagoa Tanque da Fazenda. Diferente da dinâmica de ocupação do habitat, como citado por Pott \& Pott (2000), essa espécie foi observada durante todo o período do estudo, sempre com grande proliferação submersa. Provavelmente, a ocupação foi devido à característica límpida dessa lagoa.

Mayaca fluviatilis também esteve presente nas lagoas Tanque da Fazenda e Comprida, entretanto ocorrendo com formas biológicas diferenciadas. $\mathrm{Na}$ lagoa Comprida, formava um emaranhado submerso 
e nas margens adquiria as formas emergente ou anfíbia. Por outro lado, na lagoa Tanque da Fazenda essa espécie foi observada apenas nas formas anfíbia ou emergente. Possivelmente, a dominância de E. minima nesse ambiente influenciou na ocupação de $M$. fluviatilis na forma submersa. Segundo Camargo et al. (2003), a disponibilidade de luz pode exercer grande influência na composição de espécies e, conforme observado no presente estudo, a dominância de uma determinada espécie pode também ter influência na colonização de diferentes formas biológicas.

No presente estudo, provavelmente as características físico-químicas da água e as influências de aspectos físicos dos ambientes foram determinantes para a composição florística. Enquanto nas áreas com maior disponibilidade de nutrientes (Lagoas Americana e Estivinha), foram associadas espécies de ampla ocorrência (Typha domingensis, Nymphaea ampla, Eleocharis interstincta, Nymphoides indica e Polygonum hydropiperoides), nos ambientes lóticos ocorreram espécies restritas (Ericaulon aquatile, Leiothrix fluitans e Utricularia neottioides), relacionadas às características físicas dos corpos de água (substrato rochoso e corredeiras). Desta forma, a diversidade das espécies de macrófitas aquáticas da Cadeia do Espinhaço refletiu a heterogeneidade dos ambientes, sendo algumas características fortemente determinantes para sua ocorrência.

\section{Agradecimentos}

Ao Fundo Nacional do Meio Ambiente (FNMA), pelo financiamento do estudo. Aos colegas do Setor de Recursos da Terra e Recursos da Água/ Cetec pelo apoio logístico e coletas. À Edna Bueno pela confecção do mapa. À Sandra Francischetti Rocha e Helena Ferreira pelas discussões das variáveis físico-químicas da água.

\section{Referências}

APHA - American Public Health Association. Biological examination of water. 1995. 16 ed. APHA, AWWA,WPCF, Washinton. Pp. 1041-1215.

Bacchi, O.; Leitão Filho, H.F. \& Aranha, C. 1984. Plantas invasoras de cultura. Vol. 3. Instituto Campineiro de Ensino Agrícola, Campinas. 308p.

Benassi, R.F.; Pezzato, M.M. \& Camargo, A.F.M. 2001. Produção primária da macrófita aquática Cabomba furcata Schul. \& Schult. F. em dois rios da bacia do rio Itanhém, SP. In: Congresso Brasileiro de Limnologia, 8. Resumos. Sociedade Brasileira de Limnologia, Universidade Federal da Paraíba, João Pessoa. 2000p.
Bianchini Júnior, I. 2003. Modelos de crescimento e decomposição de macrófita aquáticas. In: Thomaz, S.M.\& Bini, L.M. (eds.). Ecologia e manejo de macrófitas aquáticas EDUEM, Maringá. Pp. 85-126.

Botrel, R.T.; Oliveira-Filho, A.T.; Rodrigues, L.A. \& Curi, N. 2002. Influência do solo e topografia sobre as variações da composição florística e estrutura da comunidade arbóreo-arbustiva de uma floresta estacional semidecídua em Ingaí. Revista Brasileira de Botânica 25: 195-213.

Brandão, M.; Laca-Buendia, J.P. \& Gavillanis, M.L. 1989. Plantas palustres e aquáticas que se comportam como invasoras, no estado de Minas Gerais. Acta Botanica Brasilica 2: 255-266.

Brigante, J.; Espíndola, E.L.G.; Povinelli, J. \& Nogueira, A.M. 2003. Caracterização física, química e biológica da água do rio Mogi-Guaçu. In: Brigante, J. \& Espíndola, E.L.G. (eds.). Limnologia fluvial. Rima, São Paulo. Pp. 55-75.

Camargo, A.F.M.; Pezzato, M.M. \& Henry-Silva, G.G. 2003. Fatores limitantes à produção primária de macrófitas aquáticas. In: Thomaz, S.M. \& Bini, L.M. (eds.) Ecologia e manejo de macrófitas aquáticas. EDUEM, Maringá. Pp. 59-84.

Causton, D.R. 1988. An introduction to vegetation analysis, principle and interpretation. Unwin Hyman, London. 342p.

CETEC - Fundação Centro Tecnológico de Minas Gerais. 1983. Diagnóstico ambiental do estado de Minas Gerais. Série Publicações Técnicas. CETEC, Belo Horizonte. 158p. il.

COPAM-Conselho Estadual de Política Ambiental; CERHMG - Conselho Estadual de Recursos Hídricos do Estado de Minas Gerais. 2008. Deliberação Normativa Conjunta COPAM/CERH-MG n ${ }^{\circ} 01$, de 05 de maio de 2008. Dispõe sobre a classificação dos corpos de água e diretrizes ambientais para o seu enquadramento, bem como estabelece as condições e padrões de lançamento de efluentes, e dá outras providências. Disponível em $<$ http://www.siam.mg.gov.br/sla/download.pdf?id Norma=8151>. Acesso em 3 Out 2011.

Cook, C.D.K. 1996. Aquatic Plant Book. Amsterdam/ New York, SPB Academic Publishing. 229p.

Drummond, G.M.; Martins, C.S.; Machado, A.B.M.; Sebaio, F.A. \& Antonini, Y. 2005. Biodiversidade em Minas Gerais: um atlas para sua conservação. 2 ed. Fundação Biodiversitas, Belo Horizonte. 222p.

Esteves, F.A. 1998a. Considerations on the ecology of wetlands, with emphasis on Brazilian floodplain ecosystems. In: Scarano, F.R. \& Franco, A.C. (eds.). Ecophysiological strategies of xerophytic and amphibious plants in the neotropics. Series Oecologia Brasiliensis, V.IV. PPGE-UFRJ, Rio de Janeiro. Pp. 111-135.

Esteves, F.A. 1998b. Fundamentos de limnologia. 2 ed. Interciência, Rio de Janeiro. 602p. 
Fromm-Trinta, E. 1996. Flora da Serra do Cipó, Minas Gerais: Lentibulariaceae. Boletim de Botânica da Universidade de São Paulo 15:105-18.

Giulietti, A.M.; Menezes, N.L.; Pirani, J.R.; Meguro, M. \& Wanderley, M.G.L. 1987. Flora da Serra do Cipó, Minas Gerais: caracterização e lista das espécies. Boletim de Botânica da Universidade de São Paulo 9: 1-151.

Haslam, S.M. 1978. River plants. University Press, Cambridge. 396p.

Henry-Silva, G.G. \& Camargo, A.F.M. 2000. Composição química de quatro espécies de macrófitas aquáticas e possibilidades de uso de sua biomassa. Naturalia 25:111-125.

Leitão Filho, H.F.; Bacchi, O. \& Aranha, C. 1972. Plantas invasoras de culturas no estado de São Paulo. Vol. 1. Hucitec, São Paulo. 2820p.

Leitão Filho, H.F.; Bacchi, O. \& Aranha, C. 1975. Plantas invasoras de culturas no estado de São Paulo. Vol. 2. Hucitec, São Paulo.

Lorenzi, H. 2000. Plantas daninhas do Brasil: terrestres, aquáticas, parasitas e tóxicas. $3^{\mathrm{a}} \mathrm{ed}$. Instituto Plantarum, Nova Odessa. 608p.

MacCune, B. \& Mefford, M.J. 1999. PC-ORD version 4.0, Multivariate analysis of ecological data, Users guide. MjM Software Desing, Glaneden Beach.

Meerhoff, M. \& Mazzeo, N. 2004. Importancia de las plantas flotoantes libres de gran porte en la conservación y rehabilitación de lagos someros de Sudamérica. Ecossistemas 2004/2. Disponível em <http://www.aeet.org/ecossistemas/042/ revision $1 . h t m>$.

Meyer, S.T. \& Franceschinelli, E.V. 2010. Estudo florístico de plantas vasculares associadas às áreas úmidas da Cadeia do Espinhaço (MG), Brasil. Revista Brasileira de Botânica 33: 677-691.

Murphy, K.J. 2000. Predizendo alterações em ecossistemas aquáticos continentais e áreas alagáveis: o potencial de sistemas bioindicadores funcionais utilizando macrófitas aquáticas.
Maringá: Boletim da Sociedade Brasileira de Limnologia 27:7-9.

Neiff, J.J. 1997. Aspectos conceptuales para la evalucion ambiental de tierras humedas continentales de America del Sur. Anais do VIII Seminário Regional de Ecologia. Programa de Pós Graduação em Ecologia e Recursos Naturais UFSCar, São Carlos. Pp. 1-18.

Palma-Silva, C. 1998. Crescimento e produção de Typha domingensis Pers na lagoa Imboassica. In: Esteves, F.A. (ed.). Ecologia das lagoas costeiras do Parque Nacional da Restinga de Jurubatiba e do município de Macaé (RJ). Universidade Federal do Rio de Janeiro, Rio de Janeiro. Pp. 205-220.

Pedralli, G. 1990. Macrófitos aquáticos: técnicas e métodos de estudos. Estudos de Biologia 26: 5-24.

Pollock, M.M.; Naiman, R.J. \& Hanley, T.A. 1998. Plant species richness in riparian wetlands - a test of biodiversity theory. Ecology 79: 94-105.

Pott, V.J. \& Pott, A. 2000. Plantas aquáticas do Pantanal. Embrapa, Brasília . 404p.

Røslett, B. 1988. An integrated approach to hydropower impact assessment. I. Environmental features of some Norwegian hydrolectric lakes. Hydrobiologia 164: 39-66.

Sculthorpe, C.D. 1967. The biology of aquatic vascular plants. St. Martins Press, New York. 160p.

ter Braak, C.J.F. 1988. Canoco a Fortran program for canonical community ordination by (partial) (detrended) (canonical) correspondense analysis, principal components analysis and redundancy analysis (Version 2.1). Institute of Applied Computer Science, Wageningen. 95p.

Thomaz, S.M. \& Bini, L.M. 1999. A expansão das macrófitas aquáticas e implicações para o manejo de reservatórios: um estudo na represa de Itaipu. In: Henry, R. (ed.). Ecologia de reservatórios: estrutura, função e aspectos sociais. FAPESP/FUNDIBIO, Botucatu. Pp. 599-625. 